\title{
Exercise based evaluations and interventions for pulmonary hypertension with connective tissue disorders
}

\begin{abstract}
:
Introduction: Exercise intolerance is a common and often significant limitation in pulmonary arterial hypertension (PAH). This intolerance greatly affects the quality of life and function of the individual with PAH, irrespective of its etiology. In PAH associated with connective tissue disorders (PAH-CTD), exercise intolerance is further amplified by the presence of co-existing musculoskeletal manifestations of CTD. The evaluation of exercise capacity and prescription for exercise training therefore becomes a challenge to the clinician. Areas covered: This review highlights factors contributing to exercise intolerance in PAH-CTD, evaluation methods of exercise capacity and an overview on exercise training and a roadmap for future research Expert opinion/commentary: Exercise intolerance is a complex interplay of cardiovascular, pulmonary and musculoskeletal systems. Data from cardiopulmonary exercise tests have shown predictive abilities for both diagnosis and prognosis. In its absence, the six minute walk test can be used to provide similar information thereby making the role of exercise testing an invaluable evaluation method in PAH-CTD. Exercise training data in PAH-CTD is still sparse, though, data from PAH studies suggest potential benefit. However, more research is required in this area of testing and training for greater understanding on exercise haemodynamic, phenotypes and training benefits.
\end{abstract}

Keywords: cardiopulmonary exercise testing, six minute walk test, pulmonary arterial hypertension, systemic sclerosis, Rheumatology

Running title: Exercise in pulmonary hypertension 


\section{Introduction:}

Pulmonary hypertension $(\mathrm{PH})$ is a condition that causes exercise intolerance, often to severe levels, thereby affecting function and quality of life.[1] Clinically, PH has been classified into five distinct etiological groups.[2] Among them, pulmonary arterial hypertension (PAH) from connective tissue disorders (CTD) or PAH-CTD are classified under group 1; more specifically, group 1.4.1.

Among the various CTDs, systemic sclerosis (SSc), systemic lupus erythematosus (SLE), primary Sjogrens syndrome (PSS) and rheumatoid arthritis (RA) are some of the conditions which can result in PAH. PAH occurs most often in association with SSc and even SLE.[3,4] The presence of CTD in PAH has been found to result in worse outcomes when compared to individuals without $\mathrm{CTD}[5]$ and even when compared to those with idiopathic PAH (iPAH).[6] Thus, there is a need for early identification of PAH in CTDs.

This paper therefore aims to review the various pathways that contribute to exercise intolerance and how they are evaluated using exercise based evaluation methods, while summarizing recent evidence for exercise testing and training of PAH-CTD.

\section{Pulmonary arterial hypertension:}

\subsection{Central factors (Cardiovascular and pulmonary):}

Individuals with PH have a marked reduction in exercise capacity with a lower peak oxygen uptake $\left(\dot{\mathrm{V}}_{2}\right)$. [1,8] Sun and colleagues identified two pathways (i.e. central and peripheral limitations) limiting peak exercise performance.[9] For various etiologies of pulmonary hypertension, interactions between the various physiological systems have been thought to contribute to exercise intolerance.[1] Centrally, the pulmonary circulation is a low-pressure system required to accommodate the entire cardiac output. In healthy individuals, during 
exercise, there is an increase in cardiac output and a fall in both the pulmonary vascular resistance (PVR) and right ventricular (RV) afterload. Traditionally, it has been thought that in PH, PVR fails to fall which in turn markedly worsens RV afterload. Recently, the impact of the pulmonary vascular resistance (PVR: identified as the ratio between the cardiac output and mean PAP) has been thought to be a crucial factor limiting exercise performance.[10] In response to the elevated PAP in PH the RV undergoes complex remodeling which, over time, results in reduced contractility and a failure to augment RV and eventually left ventricular (LV) stroke volume (SV) during exercise.[11]

Along with these cardiac related factors, flow dynamics in the pulmonary vascular system plays an important role in limiting exercise performance. A minimal alteration in the radius of the vessel can alter the resistance of the pulmonary circulation four-fold.[12] These alterations in PVR further impact the RV thereby altering the normal contractile mechanics and causing vascular congestion.[13] As a result there is a well-documented ventricular-arterial uncoupling and reduction in RV exercise contractile reserve, that is further exacerbated with exercise.[14-16]

\subsection{Peripheral factors (including muscles and cellular mechanisms):}

Apart from these central changes, evidence suggests that in $\mathrm{PAH}$ there is a reduced skeletal muscle oxidative capacity[17] and a lower proportion of Type I fibers. During exercise, the lower oxidative capacity results in a greater buildup of metabolites (including lactate) resulting in early onset of fatigue.[18] This leads to an increased firing of mechanoreceptors /metaboreceptors (ergoreceptors) in the skeletal muscle which, via afferent feedback to the brainstem, increases the ventilatory drive. Hence, not only is there a reduced delivery of $\mathrm{O}_{2}$ to the 
exercising muscle, but there is also a decrease in the capacity of the muscle to utilize $\mathrm{O}_{2}$ delivered to it. Furthermore, mitochondrial dysfunctions (e.g., microRNA-126) further alter angiogenesis and vascular integrity thereby decreasing the $\mathrm{O}_{2}$ delivery capacity, resulting in exercise intolerance.[19]

\section{Pulmonary arterial hypertension with connective tissue disorders:}

\subsection{Central factors (Cardiovascular and pulmonary):}

In PAH-CTD, the mechanisms for exercise intolerance are different. Most CTDs, irrespective of the cause, tend to affect the pulmonary system and cause interstitial lung disease.[20,21] In addition, many of them also suffer from co-morbid conditions such as cardiovascular disease (17\% and 67\% among survivors and deceased respectively) [22] and cardiac anomalies such as LV dysfunction (25.6\%)[23], valvular regurgitation (aortic or mitral) (60\%) along with changes to the LV structure.[24,25] These cardiovascular conditions in the long run could result in heart failure and further reduce exercise tolerance.

As observed in PAH, the RV plays a vital role in contributing to exercise intolerance. When estimating the degree of involvement of the RV, it has been seen that those with SSc had a greater reduction in RV contractility than compared to those with idiopathic PAH.[26,27] Functional reserve of the RV, which is a determinant of exercise capacity, has been found to be greatly depressed in PAH-CTD, when compared to PAH.[26,28] During exercise there is some evidence of dilatation of the RV in PAH-CTD but not in PAH.[28] It was also found that in PAH-CTD, SSc creates an intrinsic RV dysfunction which further contributes to the marked exercise intolerance. 
Additionally, the endothelial dysfunction associated with CTD further affects the pulmonary vasculature and the lungs.[29] Pulmonary vasculopathy in SSc, greatly impairs the vessels ability to dilate during exercise, and impairs SV and cardiac output with sub-maximal exercise testing. [30] Among the various PAH-CTD, reduced diffusion capacities have further been observed. [31] As a result, individuals have a reduced arterial $\mathrm{O}_{2}$ content and substantial reduction in the $\mathrm{O}_{2}$ carrying capacity of the blood. Such changes influence symptoms such as dyspnea, which has been found to be a major factor contributing to their disability.[33] Another key feature of the PAH-CTD is the advancing age (PAH-CTD: $55 \pm 13$ vs IPAH: $46 \pm 15 \mathrm{yr}$ ) and reduced exercise capacity ( $\dot{\mathrm{VO}}_{2}$ : PAH-CTD: $0.82 \pm 0.25$ and $0.87 \pm 0.30$ vs IPAH: $1.10 \pm 0.411 . \mathrm{min}^{-1}$ ) during the six minute walk test.[34,35]

\subsection{Peripheral factors (including muscles and cellular mechanisms):}

Along with these central mechanisms, skeletal muscle dysfunctions have been reported in young adolescent children with mixed CTD.[36] Patients with scleroderma have been found to have significant muscle weakness which has been seen to greatly impact their disability.[37] Additionally, microangiopathy has been found to be present in SSc related myopathy.[38] These muscle dysfunctions could also result from peripheral vascular dysfunctions, thereby affecting peripheral muscle function. [39,40] Endothelial function maybe further hampered in the setting of PAH,[41] thereby contributing to impaired exercise tolerance. Muscle weakness, in the setting of co-existing $\mathrm{PH}$, will only worsen the $\mathrm{O}_{2}$ extraction from the muscles as has been shown in PAH.[1] A comparison of the various limiting factors in both PAH and PAH-CTD are summarized in Figure 1. 


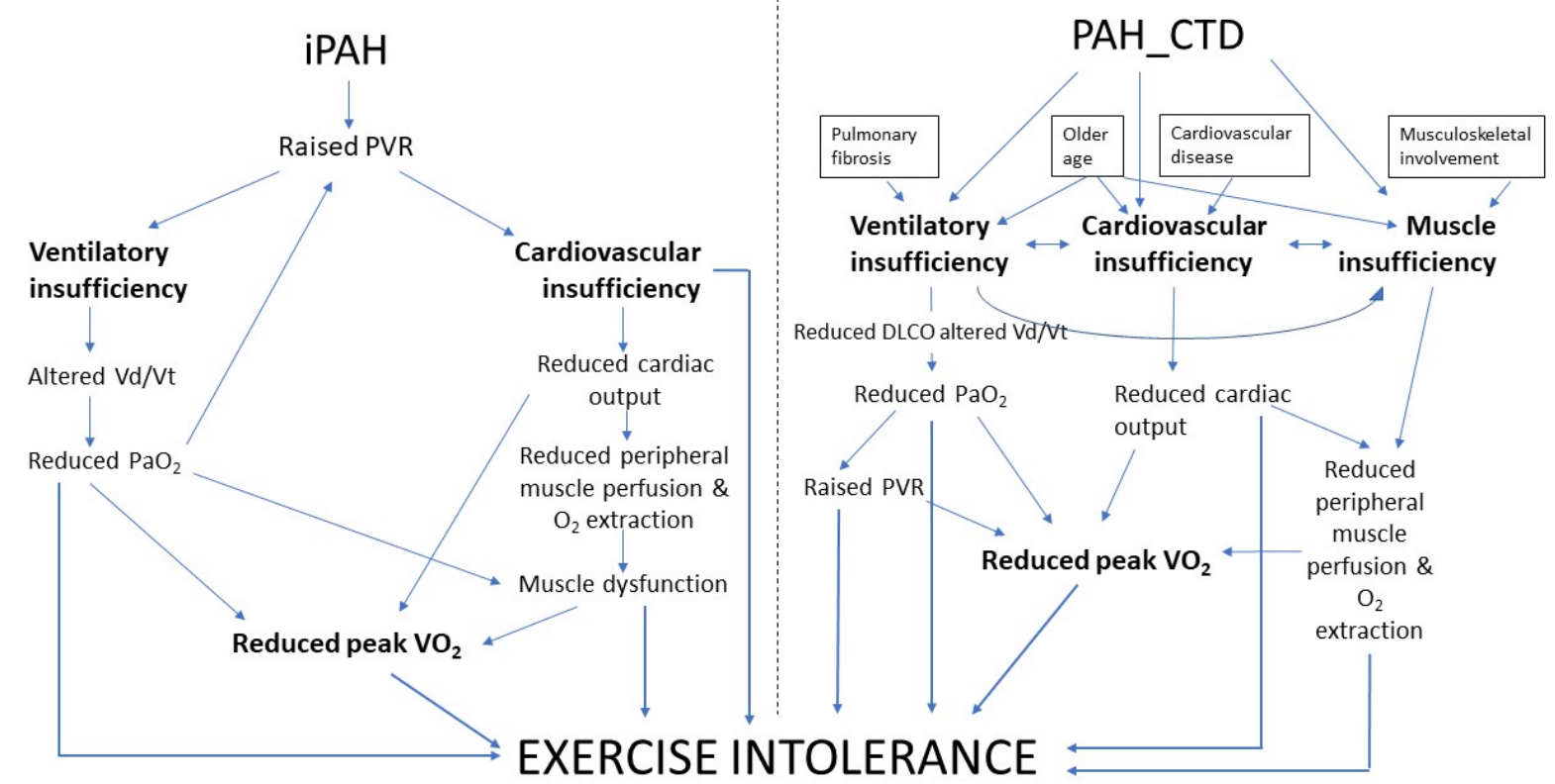

Figure 1. Comparison of various mechanisms resulting in exercise intolerance in PAH_CTD and IPAH

\section{Methods for evaluation of exercise capacity in PAH}

Evaluation of exercise capacity in PAH is recommended in the recent clinical guidelines for the assessment of PAH.[42] The recommendations have relied on 6 minute walk test (6MWT) distance (6MWD) and particular key variables obtained from cardiopulmonary exercise testing (CPX). The variables from CPX have also been recommended by the European Association of Cardiovascular Prevention and Rehabilitation (EACPR) along with the American Heart Association (AHA).[43]

\subsection{Cardiopulmonary exercise test:}

CPX is the gold standard for evaluating exercise capacity. It requires the use of an ergometer (typically a treadmill or stationary cycle) along with a metabolic system capable of measuring 
oxygen uptake using open circuit spirometry. Various protocols have been used to assess exercise capacity such as the Naughton protocol, Balke protocol (both treadmill) and Ramped (cycle ergometer) protocols. Irrespective of the type of protocol, they all generally have a warm up period, followed by a progressive increase in workloads.[44] Regardless of the mode of testing, monitoring patients for heart rate, rhythm and haemodynamics are crucial.[45] Prior to starting the test, it is essential to ensure participants are prepared adequately and screened as recommended.[44] In addition, the testing center should be adequately staffed and have access to emergency resuscitation equipment as well.[45]

CPX provides the clinician with a wealth of information and provides a non-invasive assessment of the ventilation - perfusion abnormalities commonly seen in PH.[43] A summary of the various responses obtained from CPX are summarized in Table 1. In addition to these exercise variables, symptoms and haemodynamics need to be assessed. Recently, the use of invasive haemodynamic measurements during CPX have also been employed with greater frequency and they have specific guidelines.[46] Whilst less frequently used than the six minute walk test to assess functional capacity, standard CPX continues to remain the gold standard for assessing cardiorespiratory fitness and is part of various $\mathrm{PH}$ specialty centers.[47]

Table 1: Variables obtained from cardiopulmonary exercise testing

\begin{tabular}{|l|l|}
\hline Variable & Description \\
\hline $\begin{array}{l}\text { Peak oxygen consumption }\left(\text { peak } \mathrm{VO}_{2}\right), \\
\mathrm{ml} / \mathrm{Kg} / \mathrm{min}\end{array}$ & $\begin{array}{l}\text { The highest value of } \mathrm{O}_{2} \text { uptake during } \\
\text { exercise }\end{array}$ \\
\hline Anaerobic threshold (AT) & $\begin{array}{l}\text { Non-linear increase in pulmonary ventilation } \\
\text { in relation to } \mathrm{VO}_{2}\end{array}$ \\
\hline $\begin{array}{l}\text { Ventilatory efficiency }\left(\mathrm{VE} / \mathrm{VCO}_{2} \text { slope), }\right. \\
\mathrm{L} / \mathrm{min}\end{array}$ & $\begin{array}{l}\text { Represents the balance between ventilation } \\
\text { and perfusion }\end{array}$ \\
\hline Peak respiratory exchange ratio (RER) & $\begin{array}{l}\text { The ratio between } \mathrm{VCO}_{2} \text { and } \mathrm{VO}_{2} \text { and } \\
\text { indicates effort during CPX }\end{array}$ \\
\hline End tidal $\mathrm{CO}_{2}\left(\mathrm{P}_{\mathrm{ET}} \mathrm{CO}_{2}\right), \mathrm{mm} \mathrm{Hg}$ & $\begin{array}{l}\text { Represents the balance between ventilation } \\
\text { and perfusion }\end{array}$ \\
\hline
\end{tabular}




\begin{tabular}{|l|l|}
\hline $\mathrm{O}_{2}$ pulse $(\mathrm{ml} /$ beat $)$ & $\begin{array}{l}\text { The ratio between } \mathrm{VO}_{2}\left(\mathrm{mLO}_{2} / \mathrm{min}\right) \text { and heart } \\
\text { rate }(\mathrm{HR}-\mathrm{bpm})\end{array}$ \\
\hline Peak heart rate (beats/min) & The highest heart rate achieved \\
\hline Heart rate recovery in $1^{\text {st }}$ minute (beats) & $\begin{array}{l}\text { Represents the function of autonomic system } \\
\text { (parasympathetic system) }\end{array}$ \\
\hline $\mathrm{Spo}_{2}(\%)$ & $\begin{array}{l}\text { It is an indirect estimate of arterial } \\
\text { oxygenation }\end{array}$ \\
\hline
\end{tabular}

Despite the high yield of information obtained from CPX, performing a CPX is not always feasible, especially in low resource settings. The projected costs for establishing a CPX lab in 2013 were at USD 50,000.[48] Considering inflation, this would no doubt be a conservative estimate. Moreover expertise is required to run these tests and there is some evidence to suggest that CPX is less reliable in centers less familiar with the conducting these types of tests.[49] Thus, there is also a need to use alternate exercise evaluation methods such as the standard treadmill tests without breath-by-breath gas analysis or simple walk tests like the 6MWT. The standard treadmill test has been employed in PAH and has been found to be a useful tool, even without the breath-by-breath analysis.[50] When echocardiography supplemented the standard treadmill test, it was seen that a better understanding of the RV response to exercise (e.g., RV contractile reserve) can be assessed better which in turn provides early insight into the development of PAH-CTD in SSc.[51]

\subsection{Six minute walk test:}

The 6MWT is the most common clinical outcome measure of exercise capacity that assesses an individuals' submaximal functional capabilities. Initial guidelines for standardization were put forward by the American Thoracic Society (ATS) and recently updated by a joint statement of the ATS and ERS.[52,53] Using standardized instructions, the subject is asked to walk as far as possible in six minutes using a 30meter walkway or corridor. Oxygen saturation, breathlessness 
and heart rate are measure prior, during and at the completion of the test. Rest is allowed and if walking aids are used, a note of it should be included in the testing document. The 6MWT has been found to be reliable, with intraclass correlation coefficient values ranging between 0.72 and 0.99.[54] The outcome of the test is the total distance covered, usually expressed in meters. The predicted distance to be covered has been established in various populations, however these equations remain specific to disease population and the country of origin.[55] Moreover there is a well-defined minimally important difference $(33 \mathrm{~m})$ for the increase in 6MWD for individuals with PAH.[56] However, the absolute distance may not be a true reflection of that person's ability in CTD, as pain and musculoskeletal factors could greatly limit the performance.[57]

The change in resting to post $6 \mathrm{MWT} \mathrm{O}_{2}$ saturation has been used to help quantify disease severity in scleroderma patients with pulmonary manifestations.[58] This has great importance as the severity of desaturation has been found to be closely related to pulmonary diffusion.[59] Recently, stress echocardiography after the 6MWT has been found to be a predictor of future development of PAH-CTD (mean pulmonary artery pressure (mPAP): HR 1.15, 95\% CI:1.051.25, $\mathrm{p}=0.002 ; \mathrm{mPAP} /$ cardiac output $(\mathrm{Q})$ : HR 1.49 (95\% CI: 1.21-1.85), $\mathrm{p}=0.001 ; \Delta \mathrm{mPAP} / \Delta \mathrm{Q}$ : HR 1.10 (95\%CI: 1.04-1.16), $\mathrm{p}=0.005)$.[60] Therefore, in addition to the distance covered, assessing these aspects of desaturation and cardiac function maybe more relevant while assessing PAH-CTD.

\section{Exercise predictors of PAH in CTDs:}

\subsection{Diagnostic role:}


Evaluation of patients with CTD has been recommended according to the evidence-based detection of PAH in SSc (DETECT) guidelines including non-echocardiographic assessments followed by echocardiographic evaluation and right heart catheterization.[61] The DETECT study included only non-invasive variables like pulmonary function, serum biomarkers and exercise electrocardiograms. However, CPX is now recommended for the evaluation of patients with suspected or confirmed PAH/secondary PH and is a Level B, class IIa recommendation for diagnostic evaluation.[43,62] These guidelines proposed risk stratification based on peak $\mathrm{VO}_{2}$, the minute ventilation/carbon dioxide production $\left(\dot{\mathrm{V}}_{\mathrm{E}} / \mathrm{V} \mathrm{CO}_{2}\right)$ slope and the partial pressure of end-tidal carbon dioxide $\left(\mathrm{P}_{\mathrm{ET}} \mathrm{CO}_{2}\right)$ values obtained during exercise testing. Additionally, $\mathrm{CPX}$ variables also help determine the cause for exercise limitation (respiratory limitation, left ventricular dysfunction or pulmonary vasculopathy).[23] Thus, these values obtained from CPX, make the evaluation of PAH-CTD crucial. Apart from CPX, the absolute distance walked on the 6MWT has been shown to be significantly lower among those with SSc and PH than those with only SSc (288m [95\% CI: $259-317 \mathrm{~m}$ ] versus (430m [95\% CI: 402-458m] respectively).[63] Along with distance, desaturation during the 6MWT is also of importance in PAH-CTD.[58]

\subsection{Prognostic role:}

The prognostic role of CPX variables in assessing survival in PAH has also been demonstrated with a building evidence base.[48,62] Furthermore, the use of CPX has recently been considered a Level B, class IIb recommendation for prognostication.[62] The most commonly obtained variable from $\mathrm{CPX}$, peakVO $\mathrm{VO}_{2}$ has shown the highest diagnostic accuracy (sensitivity $87.5 \%$, specificity $74.8 \%$ at a threshold level of $13.8 \mathrm{~mL} / \mathrm{min} / \mathrm{kg}$.[64] Recently, lower levels of $\mathrm{P}_{\mathrm{ETCO}}$ have been found to be associated with shorter survival among patients having hereditary or PAH- 
CTD when compared to those with heart or valve disease related PH.[65] The $\dot{\mathrm{V}}_{\mathrm{E}} / \dot{\mathrm{V}} \mathrm{CO}_{2}$ slopes have also been used as an indicator for stratifying risk. Additionally, dyspnea and diffusion capacity of the lungs for carbon monoxide (DLCO), could be predictors of PH in SLE.[66] Additionally, Minai and colleagues recently demonstrated an impaired heart rate recovery in the first minute following the 6MWT was associated with an increased risk of clinical worsening (hazard ratio [HR]: 6.4 [95\% confidence interval (CI): 2.6-19.2]; $\mathrm{P}<0.0001]$, hospitalization

(HR: 6.6 [95\% CI: 2.4-23]; P < 0.0001) and death (HR: 4.5 [95\% CI: 1.6-15.7]; P = 0.003).[67] This suggests that in addition to measurement of the distance covered during the 6MWT, desaturation and heart rate recovery (a surrogate marker of autonomic function) may need to be measured and documented. Moreover, we recently combined the measurement of gas exchange with the 6MWT which provided not only information on the 6MWD but also key gas exchange measures such as $\dot{\mathrm{V}}_{\mathrm{E}} / \dot{\mathrm{V} C O} \mathrm{C}_{2}$ slope and $\mathrm{P}_{\mathrm{ET}} \mathrm{CO}_{2 .}$.[35] Whilst the clinical efficacy of this approach is yet to be validated, it may be this combination of walk distance and gas exchange measurements may be more sensitive to disease progression.

Adjuncts like echocardiography performed after a 6MWT have been shown to be predictive of developing PH based on early diastolic tricuspid annulus motion velocity (HR: $0.79 ; \mathrm{p}=0.025)$, and $\Delta$ mean PA $/ \Delta$ cardiac output by 6 MWD (HR: $1.10 ; p=0.005)$. [60] Thus, the prognostic value of these various exercise related variables have been demonstrated, making them useful adjuncts to the standard evaluation methods for PAH-CTD.

\section{Evidence for exercise training in PAH secondary to CTD}


In recent years, there has been an increase in trials focusing on exercise training in $\mathrm{PH}$. Recent systematic reviews and meta-analyses have shown significant benefits with exercise training across the spectrum of pulmonary hypertension.[68-70] Although only one study has focused specifically on patients with CTD,[34] many of the studies in the reviews have included patients with CTD.[71-74] A summary of the various studies and their interventions are given in Table 2. In the one study by Grunig et al., which focused on PAH -CTD,[34] 22 patients with PAH-CTD underwent a 3-week supervised, in-hospital exercise program followed by a 12-week homebased program which included aerobic, resistance, respiratory muscle training along with yoga. 6MWD improved by $67 \mathrm{~m}$ and $71 \mathrm{~m}$ following 3 and 12 weeks of exercise training respectively.[34] This was also reflected by an improved peak $\dot{\mathrm{VO}}_{2}$ and quality of life. Survival analysis showed a survival rate of $100 \%$ after 1 and 2 years, and $80 \%$ after 3 years. This initial work provides important support for exercise training in patients with PAH-CTD. However there remains a lack of high quality evidence (i.e., randomized controlled trials) for exercise training in $\mathrm{PH},[70]$ with a lack of focus for outpatient based studies[70] and as such the most recent statement on the recommendation for exercise training remaining as moderate (IIb).[42] In addition to exercise training, it would also be useful to target specific problems related to pain, limited range of movement and muscle weakness, which are commonly seen in CTD. Targeted inspiratory muscle training may be another possible mode of exercise training which may benefit CTD subjects with underlying respiratory dysfunction, however evidence supporting this approach is lacking and thus should be considered while prescribing conditioning exercises in PAH-CTD. 
Table 2. Summary of the various studies on exercise training including patients having PAH-CTD.

\begin{tabular}{|c|c|c|c|c|c|c|}
\hline Author (year) & Study design & $\begin{array}{l}\text { Total sample } \\
\text { size/Sample } \\
\text { with CTD }\end{array}$ & Etiology & $\begin{array}{l}\text { WHO } \\
\text { functional } \\
\text { classa }\end{array}$ & Intervention details & Resultsb \\
\hline $\begin{array}{l}\text { Shoemaker et } \\
\text { al. (2009) } 45\end{array}$ & Case report & 2-Jan & Scleroderma & II & $\begin{array}{l}\text { Cycle ergometry at } 50 \% \text { peak } \\
\text { workload }\end{array}$ & $\begin{array}{l}\text { Increased peak VO2 and improved } \\
\text { quality of life }\end{array}$ \\
\hline $\begin{array}{l}\text { Fox et al. } \\
(2011) 46\end{array}$ & $\begin{array}{l}\text { Non- } \\
\text { randomized } \\
\text { controlled trial } \\
\end{array}$ & 22-Sep & CTD & $\| \mathrm{IIII}$ & $\begin{array}{l}\text { Interval training, continuous } \\
\text { aerobic training, resistance } \\
\text { training + home based brisk } \\
\text { walking and stair climbing at } \\
60-80 \% \text { HRmax }\end{array}$ & Increased 6MWD and peak VO2 \\
\hline $\begin{array}{l}\text { Grunig et al. } \\
\text { (2011)47 }\end{array}$ & $\begin{array}{l}\text { Single group, } \\
\text { pre-post }\end{array}$ & $58 / 2$ & $\begin{array}{l}\text { Collagen vascular } \\
\text { disease }\end{array}$ & II-IV & $\begin{array}{l}\text { Aerobic exercise at } 60-80 \% \\
\text { peak } \mathrm{VO} 2 \text {, resistance training at } \\
0.5-1 \mathrm{~kg} \text { and respiratory muscle } \\
\text { training }\end{array}$ & $\begin{array}{l}\text { Increased 6MWD, peak VO2 and } \\
\text { improved quality of life }\end{array}$ \\
\hline $\begin{array}{l}\text { Grunig et al. } \\
(2012) 44\end{array}$ & $\begin{array}{l}\text { Single group, } \\
\text { pre-post }\end{array}$ & $21 / 21$ & CTD & II-IV & Same as Grunig et al (2011) & $\begin{array}{l}\text { Increased 6MWD and improved } \\
\text { quality of life }\end{array}$ \\
\hline $\begin{array}{l}\text { Chan et al. } \\
(2013) 48\end{array}$ & $\mathrm{RCT}$ & $23 / 17$ & $\begin{array}{l}\text { Scleroderma, SLE, } \\
\text { Sjogrens } \\
\text { syndrome, RA and } \\
\text { Mixed CTD }\end{array}$ & I-IV & $\begin{array}{l}\text { Treadmill walking at } 70-80 \% \\
\text { heart rate reserve + Education } \\
\text { vs. Education alone }\end{array}$ & $\begin{array}{l}\text { Improved 6MWD, } \\
\text { cardiorespiratory function and } \\
\text { quality of life }\end{array}$ \\
\hline $\begin{array}{l}\text { Ley et al. } \\
\text { (2013) } 49\end{array}$ & $\mathrm{RCT}$ & Feb-20 & CTD & $\| I I I I$ & Same as Grunig et al. (2011) & Improved 6MWD \\
\hline $\begin{array}{l}\text { Kabitz et al. } \\
(2014) 50\end{array}$ & $\begin{array}{l}\text { Single group, } \\
\text { pre-post }\end{array}$ & 2-Jul & CTD & $\hat{A}$ & Same as Grunig et al. (2011) & $\begin{array}{l}\text { Improved 6MWD, inspiratory } \\
\text { muscle strength and quality of life }\end{array}$ \\
\hline
\end{tabular}

a WHO functional class is reported for the entire study cohort and specific to PAH-CTD except for reference no. 17, where the cohort included only patients with PAH-CTD. b Results are reported for the overall study and not specific to PAH-CTD except for reference no.17, where cohort included only patients with PAH-CTD.

CTD - connective tissue disorder; FITT - frequency, intensity, type and time; RA - rheumatoid arthritis; SLE - systemic lupus erythymatosis. 
Special considerations to exercise testing and training in PAH-CTD:

Although there is a strong need to evaluate exercise capacity and promote exercise training in PAH-CTD, it should be noted that PAH-CTD is also associated with various musculoskeletal disorders including joint pain, reduced range of motion in various large and small joints resulting in tightness and weakness of muscles; these affect joint stability and further predispose the individual to injury during vigorous activity. Additionally, the use of assistive devices could be a limiting factor to standard exercise testing methodology and training programs.

\section{Recommendations:}

From the review of the evidence, we propose the following recommendations for the evaluation and training of PAH_CTD.

1. CPX or a $6 \mathrm{MWT}$ are essential in the determination of factors which limit exercise performance in PAH-CTD

a. CPX will provide information on the degree of gas exchange limitation

b. In the absence of CPX, the degree of desaturation during either a standard treadmill or 6MWT would be useful

c. Musculoskeletal impairments limiting participation in stress tests or 6MWT may require modification to existing testing methods

2. Exercise training is a useful adjunct for improving exercise capacity and quality of life in $\mathrm{PAH}$

a. Limited evidence in PAH-CTD suggests beneficial effects of exercise training, however, moderate intensity exercise training involving aerobic, resistance and inspiratory muscle training may be beneficial 
b. Musculoskeletal impairments need to be considered in the development of an exercise program

\section{Conclusion:}

Evaluating exercise capacity and its related outcomes are important in PAH-CTD. Considering the non-invasive nature of these tests to predict outcomes, exercise evaluations need to find a place in the routine evaluations of PAH-CTD. Although exercise training appears to be beneficial in PAH, there are limited studies that have been performed in PAH-CTD. The challenges faced by patients with PAH-CTD need to be addressed while planning testing and training interventions. There is therefore a great need for more exercise related research to be carried out in PAH-CTD.

\section{Expert review:}

PAH in individuals with CTD is a major long-term sequela of the underlying disease. This review highlights how PAH-CTD affects function and exercise capacity and further elucidates the physiological mechanisms that result in exercise intolerance. This exercise intolerance can be evaluated through various exercise-based testing methods such as cardiopulmonary exercise testing and other clinical tests of exercise performance such as the six minute walk test. Given the current recommendations for exercise testing in $\mathrm{PAH}$, and the available evidence to suggest how it can be used to identify PAH in CTD, it is important to highlight how exercise testing can become a part of the routine evaluation of patients with CTD. However, lack of large studies does not provide strong evidence-based recommendations in this group. There is therefore a 
great need to enhance research in this area using CPX and exercise haemodynamic studies to better elucidate the changes seen with exercise and also identify stronger predictors of long term outcomes. For individuals with PAH-CTD, there is a role of exercise training - but this is based only on one study focusing on this group and extrapolated from PH studies that have included heterogenous groups of which PAH-CTD is one. There is therefore a great need to improve studies focusing on exercise training in PAH-CTD with stronger methodological rigor and long term follow up to better understand how exercise training truly affects this group. Exercise related research in this area has a bright future and has scope for great expansion in the years ahead.

\section{Five-year review:}

The evidence on exercise-based testing and interventions in PAH-CTD is still in its early stage. However, there is now a surge in evidence on how exercise testing parameters can predict future development of PAH. There is scope for more research in the areas of exercise testing and training in PAH-CTD, which will have great implications to early identification and rehabilitation of this group of individuals.

\section{Key issues:}

- Exercise intolerance is a major factor in PH-CTD

- Exercise testing using any method, is useful to evaluate exercise capacity in PH-CTD and can also be used to predict onset of PAH in those with CTD

- Exercise training has potential as a rehabilitation intervention for those with PAH-CTD 


\section{Conflict of interest: None}

\section{Disclosures: None}

\section{REFERENCES:}

1. *Babu AS, Arena R, Myers J et al. Exercise intolerance in pulmonary hypertension: mechanism, evaluation and clinical implications. Expert Rev Respir Med, 10(9), 979-990 (2016).

A detailed paper highlighting the various physiological basis for exercise intolerance in pulmonary hypertension

2. Simonneau G, Gatzoulis MA, Adatia I et al. Updated clinical classification of pulmonary hypertension. J Am Coll Cardiol, 62(25 Suppl), D34-41 (2013).

3. Condliffe R, Howard LS. Connective tissue disease-associated pulmonary arterial hypertension. F1000prime reports, 7, 06 (2015).

4. Zhao J, Wang Q, Liu Y et al. Clinical characteristics and survival of pulmonary arterial hypertension associated with three major connective tissue diseases: A cohort study in China. Int J Cardiol, (2017).

5. Cavagna L, Codullo V, Ghio S et al. Undiagnosed connective tissue diseases: High prevalence in pulmonary arterial hypertension patients. Medicine (Baltimore), 95(39), e4827 (2016).

6. Ruiz-Cano MJ, Escribano P, Alonso R et al. Comparison of baseline characteristics and survival between patients with idiopathic and connective tissue disease-related pulmonary arterial hypertension. J Heart Lung Transplant, 28(6), 621-627 (2009).

7. Bassett DR, Jr., Howley ET. Limiting factors for maximum oxygen uptake and determinants of endurance performance. Med Sci Sports Exerc, 32(1), 70-84 (2000).

8. Fowler RM, Gain KR, Gabbay E. Exercise intolerance in pulmonary arterial hypertension. Pulmonary medicine, 2012, 359204 (2012).

9. **Sun XG, Hansen JE, Oudiz RJ, Wasserman K. Exercise pathophysiology in patients with primary pulmonary hypertension. Circulation, 104(4), 429-435 (2001).

A seminal paper which identified two mechanisms of exercise intolerance through exercise testing

10. *Kovacs G, Herve P, Barbera JA et al. An official European Respiratory Society statement: pulmonary haemodynamics during exercise. The European respiratory journal, 50(5) (2017).

A recent, detailed position statement on pulmonary haemodynamics during exercise

11. Provencher S, Herve P, Sitbon O, Humbert M, Simonneau G, Chemla D. Changes in exercise haemodynamics during treatment in pulmonary arterial hypertension. The European respiratory journal, 32(2), 393-398 (2008).

12. Arena R, Cahalin LP, Borghi-Silva A, Myers J. The effect of exercise training on the pulmonary arterial system in patients with pulmonary hypertension. Prog Cardiovasc Dis, 57(5), 480-488 (2015).

13. Naeije R, Brimioulle S, Dewachter L. Biomechanics of the right ventricle in health and disease (2013 Grover Conference series). Pulmonary circulation, 4(3), 395-406 (2014).

14. Vonk Noordegraaf A, Westerhof BE, Westerhof N. The Relationship Between the Right Ventricle and its Load in Pulmonary Hypertension. J Am Coll Cardiol, 69(2), 236-243 (2017).

15. Guazzi M, Villani S, Generati G et al. Right Ventricular Contractile Reserve and Pulmonary Circulation Uncoupling During Exercise Challenge in Heart Failure: Pathophysiology and Clinical Phenotypes. JACC. Heart failure, 4(8), 625-635 (2016). 
16. Lin AC, Strugnell WE, Seale $\mathrm{H}$ et al. Exercise cardiac MRI-derived right ventriculo-arterial coupling ratio detects early right ventricular maladaptation in PAH. The European respiratory journal, 48(6), 1797-1800 (2016).

17. Mainguy V, Maltais F, Saey D et al. Effects of a rehabilitation program on skeletal muscle function in idiopathic pulmonary arterial hypertension. J Cardiopulm Rehabil Prev, 30(5), 319323 (2010).

18. Tolle J, Waxman A, Systrom D. Impaired systemic oxygen extraction at maximum exercise in pulmonary hypertension. Med Sci Sports Exerc, 40(1), 3-8 (2008).

19. Wang $S$, Aurora AB, Johnson BA et al. The endothelial-specific microRNA miR-126 governs vascular integrity and angiogenesis. Developmental cell, 15(2), 261-271 (2008).

20. Reiseter S, Gunnarsson R, Mogens Aalokken T et al. Progression and mortality of interstitial lung disease in mixed connective tissue disease: a long-term observational nationwide cohort study. Rheumatology (Oxford, England), (2017).

21. Suzuki A, Kondoh Y, Fischer A. Recent advances in connective tissue disease related interstitial lung disease. Expert Rev Respir Med, (2017).

22. Al-Dhaher FF, Pope JE, Ouimet JM. Determinants of morbidity and mortality of systemic sclerosis in Canada. Seminars in arthritis and rheumatism, 39(4), 269-277 (2010).

23. Boutou AK, Pitsiou GG, Siakka P et al. Phenotyping Exercise Limitation in Systemic Sclerosis: The Use of Cardiopulmonary Exercise Testing. Respiration; international review of thoracic diseases, 91(2), 115-123 (2016).

24. Crozier IG, Li E, Milne MJ, Nicholls MG. Cardiac involvement in systemic lupus erythematosus detected by echocardiography. Am J Cardiol, 65(16), 1145-1148 (1990).

25. Puntmann VO, D'Cruz D, Smith Z et al. Native myocardial T1 mapping by cardiovascular magnetic resonance imaging in subclinical cardiomyopathy in patients with systemic lupus erythematosus. Circulation. Cardiovascular imaging, 6(2), 295-301 (2013).

26. Tedford RJ, Mudd JO, Girgis RE et al. Right ventricular dysfunction in systemic sclerosisassociated pulmonary arterial hypertension. Circulation. Heart failure, 6(5), 953-963 (2013).

27. Overbeek MJ, Lankhaar JW, Westerhof $\mathrm{N}$ et al. Right ventricular contractility in systemic sclerosis-associated and idiopathic pulmonary arterial hypertension. The European respiratory journal, 31(6), 1160-1166 (2008).

28. Hsu S, Houston BA, Tampakakis E et al. Right Ventricular Functional Reserve in Pulmonary Arterial Hypertension. Circulation, 133(24), 2413-2422 (2016).

29. Mathai SC, Hassoun PM. Pulmonary arterial hypertension in connective tissue diseases. Heart Fail Clin, 8(3), 413-425 (2012).

30. Rosato $E$, Romaniello A, Magri D et al. Exercise tolerance in systemic sclerosis patients without pulmonary impairment: correlation with clinical variables. Clinical and experimental rheumatology, 32(6 Suppl 86), S-103-108 (2014).

31. Someya F, Mugii N, Oohata S. Factors relating to impaired stroke volume during the 6-minute walk test in patients with systemic sclerosis. Clinical and experimental rheumatology, 34 Suppl 100(5), 152-156 (2016).

32. Chung L, Liu J, Parsons L et al. Characterization of connective tissue disease-associated pulmonary arterial hypertension from REVEAL: identifying systemic sclerosis as a unique phenotype. Chest, 138(6), 1383-1394 (2010).

33. Jaeger VK, Distler O, Maurer B et al. Functional disability and its predictors in systemic sclerosis: a study from the DeSScipher project within the EUSTAR group. Rheumatology (Oxford, England), (2017).

34. *Grunig E, Maier $\mathrm{F}$, Ehlken $\mathrm{N}$ et al. Exercise training in pulmonary arterial hypertension associated with connective tissue diseases. Arthritis research \& therapy, 14(3), R148 (2012). 
The only study on the effects of exercise training in PAH-CTD

35. Morris NR, Seale H, Harris J, Hall K, Lin AC, Kermeen F. Gas exchange responses during 6-min walk test in patients with pulmonary arterial hypertension. Respirology (Carlton, Vic.), 22(1), 165-171 (2017).

36. van der Net J, Wissink B, van Royen A, Helders PJ, Takken T. Aerobic capacity and muscle strength in juvenile-onset mixed connective tissue disease (MCTD). Scand J Rheumatol, 39(5), 387-392 (2010).

37. Paik JJ, Wigley FM, Mejia AF, Hummers LK. Independent Association of Severity of Muscle Weakness With Disability as Measured by the Health Assessment Questionnaire Disability Index in Scleroderma. Arthritis care \& research, 68(11), 1695-1703 (2016).

38. Corallo $\mathrm{C}$, Cutolo $\mathrm{M}$, Volpi $\mathrm{N}$ et al. Histopathological findings in systemic sclerosis-related myopathy: fibrosis and microangiopathy with lack of cellular inflammation. Therapeutic advances in musculoskeletal disease, 9(1), 3-10 (2017).

39. Frech T, Walker AE, Barrett-O'Keefe Z et al. Systemic sclerosis induces pronounced peripheral vascular dysfunction characterized by blunted peripheral vasoreactivity and endothelial dysfunction. Clinical rheumatology, 34(5), 905-913 (2015).

40. Mostmans Y, Cutolo M, Giddelo $C$ et al. The role of endothelial cells in the vasculopathy of systemic sclerosis: A systematic review. Autoimmunity reviews, 16(8), 774-786 (2017).

41. Rossi P, Granel B, Marziale D, Le Mee F, Frances Y. Endothelial function and hemodynamics in systemic sclerosis. Clinical physiology and functional imaging, 30(6), 453-459 (2010).

42. $*^{* *}$ Galie N, Humbert M, Vachiery JL et al. 2015 ESC/ERS Guidelines for the diagnosis and treatment of pulmonary hypertension: The Joint Task Force for the Diagnosis and Treatment of Pulmonary Hypertension of the European Society of Cardiology (ESC) and the European Respiratory Society (ERS): Endorsed by: Association for European Paediatric and Congenital Cardiology (AEPC), International Society for Heart and Lung Transplantation (ISHLT). Eur Heart J, 37(1), 67-119 (2016).

A recent position statement on the guidelines for diagnosis and management of pulmonary hypertension

43. Guazzi M, Adams V, Conraads V et al. EACPR/AHA Joint Scientific Statement. Clinical recommendations for cardiopulmonary exercise testing data assessment in specific patient populations. Eur Heart J, 33(23), 2917-2927 (2012).

44. Fletcher GF, Ades PA, Kligfield P et al. Exercise standards for testing and training: a scientific statement from the American Heart Association. Circulation, 128(8), 873-934 (2013).

45. Colquhoun D, Freedman B, Cross D et al. Clinical Exercise Stress Testing in Adults (2014). Heart, lung \& circulation, 24(8), 831-837 (2015).

46. Berry NC, Manyoo A, Oldham WM et al. Protocol for exercise hemodynamic assessment: performing an invasive cardiopulmonary exercise test in clinical practice. Pulmonary circulation, 5(4), 610-618 (2015).

47. Babu AS, Arena R, Morris NR. Evidence on Exercise Training in Pulmonary Hypertension. Advances in experimental medicine and biology, 1000, 153-172 (2017).

48. Babu AS, Myers J, Arena R, Maiya AG, Padmakumar R. Evaluating exercise capacity in patients with pulmonary arterial hypertension. Expert Rev Cardiovasc Ther, 11(6), 729-737 (2013).

49. Oudiz RJ, Barst RJ, Hansen JE et al. Cardiopulmonary exercise testing and six-minute walk correlations in pulmonary arterial hypertension. Am J Cardiol, 97(1), 123-126 (2006).

50. Hsu CH, Glassner C, Foreman AJ et al. Treadmill testing improves survival prediction models in pulmonary arterial hypertension. Am Heart J, 162(6), 1011-1017 (2011). 
51. Chia EM, Lau EM, Xuan W, Celermajer DS, Thomas L. Exercise testing can unmask right ventricular dysfunction in systemic sclerosis patients with normal resting pulmonary artery pressure. Int J Cardiol, 204, 179-186 (2016).

52. ATS statement: guidelines for the six-minute walk test. Am J Respir Crit Care Med, 166(1), 111117 (2002).

53. Holland AE, Spruit MA, Troosters T et al. An official European Respiratory Society/American Thoracic Society technical standard: field walking tests in chronic respiratory disease. The European respiratory journal, 44(6), 1428-1446 (2014).

54. Singh SJ, Puhan MA, Andrianopoulos V et al. An official systematic review of the European Respiratory Society/American Thoracic Society: measurement properties of field walking tests in chronic respiratory disease. The European respiratory journal, 44(6), 1447-1478 (2014).

55. Andrianopoulos V, Holland AE, Singh SJ et al. Six-minute walk distance in patients with chronic obstructive pulmonary disease: Which reference equations should we use? Chronic respiratory disease, 12(2), 111-119 (2015).

56. Mathai SC, Puhan MA, Lam D, Wise RA. The minimal important difference in the 6-minute walk test for patients with pulmonary arterial hypertension. Am J Respir Crit Care Med, 186(5), 428433 (2012).

57. Garin $M C$, Highland KB, Silver RM, Strange $C$. Limitations to the 6-minute walk test in interstitial lung disease and pulmonary hypertension in scleroderma. The Journal of rheumatology, 36(2), 330-336 (2009).

58. Villalba WO, Sampaio-Barros PD, Pereira MC et al. Six-minute walk test for the evaluation of pulmonary disease severity in scleroderma patients. Chest, 131(1), 217-222 (2007).

59. Rizzi M, Sarzi-Puttini P, Airoldi A, Antivalle M, Battellino M, Atzeni F. Performance capacity evaluated using the 6-minute walk test: 5 -year results in patients with diffuse systemic sclerosis and initial interstitial lung disease. Clinical and experimental rheumatology, 33(4 Suppl 91), S142-147 (2015).

60. Kusunose K, Yamada H, Hotchi J et al. Prediction of Future Overt Pulmonary Hypertension by 6Min Walk Stress Echocardiography in Patients With Connective Tissue Disease. J Am Coll Cardiol, 66(4), 376-384 (2015).

61. Coghlan JG, Denton CP, Grunig E et al. Evidence-based detection of pulmonary arterial hypertension in systemic sclerosis: the DETECT study. Annals of the rheumatic diseases, 73(7), 1340-1349 (2014).

62. *Pinkstaff SO, Burger CD, Daugherty J, Bond S, Arena R. Cardiopulmonary exercise testing in patients with pulmonary hypertension: clinical recommendations based on a review of the evidence. Expert Rev Respir Med, 10(3), 279-295 (2016).

A detailed evidence based review on cardiopulmonary exercise testing in pulmonary hypertension

63. Vandecasteele $\mathrm{E}$, De Pauw M, De Keyser F et al. Six-minute walk test in systemic sclerosis: A systematic review and meta-analysis. Int J Cardiol, 212, 265-273 (2016).

64. Dumitrescu D, Nagel C, Kovacs G et al. Cardiopulmonary exercise testing for detecting pulmonary arterial hypertension in systemic sclerosis. Heart, 103(10), 774-782 (2017).

65. Welch CE, Brittain EL, Newman AL et al. End Tidal Carbon Dioxide as a Prognostic Feature in Pulmonary Arterial Hypertension. Annals of the American Thoracic Society, (2017).

66. Perez-Penate GM, Rua-Figueroa I, Julia-Serda G et al. Pulmonary Arterial Hypertension in Systemic Lupus Erythematosus: Prevalence and Predictors. The Journal of rheumatology, 43(2), 323-329 (2016).

67. Minai OA, Gudavalli R, Mummadi S, Liu X, McCarthy K, Dweik RA. Heart rate recovery predicts clinical worsening in patients with pulmonary arterial hypertension. Am J Respir Crit Care Med, 185(4), 400-408 (2012). 
68. Pandey A, Garg S, Khunger M et al. Efficacy and Safety of Exercise Training in Chronic Pulmonary Hypertension: Systematic Review and Meta-Analysis. Circulation. Heart failure, 8(6), 1032-1043 (2015).

69. Babu AS, Padmakumar R, Maiya AG, Mohapatra AK, Kamath RL. Effects of Exercise Training on Exercise Capacity in Pulmonary Arterial Hypertension: A Systematic Review of Clinical Trials. Heart, lung \& circulation, 25(4), 333-341 (2016).

70. *Morris NR, Kermeen FD, Holland AE. Exercise-based rehabilitation programmes for pulmonary hypertension. The Cochrane database of systematic reviews, 1, CD011285 (2017).

A recent meta-analysis on exercise training in pulmonary hypertension

71. Shoemaker MJ, Wilt JL, Dasgupta R, Oudiz RJ. Exercise training in patients with pulmonary arterial hypertension: a case report. Cardiopulmonary physical therapy journal, 20(4), 12-18 (2009).

72. Fox $\mathrm{BD}$, Kassirer $\mathrm{M}$, Weiss I et al. Ambulatory rehabilitation improves exercise capacity in patients with pulmonary hypertension. J Card Fail, 17(3), 196-200 (2011).

73. Grunig E, Ehlken N, Ghofrani A et al. Effect of exercise and respiratory training on clinical progression and survival in patients with severe chronic pulmonary hypertension. Respiration; international review of thoracic diseases, 81(5), 394-401 (2011).

74. Chan L, Chin LM, Kennedy M et al. Benefits of intensive treadmill exercise training on cardiorespiratory function and quality of life in patients with pulmonary hypertension. Chest, 143(2), 333-343 (2013). 